\title{
Sulforaphane blocks hypoxia-mediated resistance to TRAIL-induced tumor cell death
}

\author{
JAE-KYO JEONG, MYUNG-HEE MOON, JAE-SUK SEO, JAE-WON SEOL, \\ YOU-JIN LEE and SANG-YOUEL PARK \\ Chonbuk National University, Center for Healthcare Technology Development, Bio-Safety Research Institute, \\ College of Veterinary Medicine, Jeonju, Jeonbuk 561-756, Korea
}

Received September 8, 2010; Accepted December 28, 2010

DOI: $10.3892 / \mathrm{mmr} .2011 .422$

\begin{abstract}
Hypoxia occurs frequently in various solid tumors and elicits a cellular response designed to improve cell survival through adaptive processes, thereby accelerating cancer progression and the development of chemotherapy resistance. Tumor necrosis factor-related apoptosis-inducing ligand (TRAIL), a member of the TNF superfamily, leads to tumor cell death via both intrinsic and extrinsic apoptotic signaling pathways. Hypoxia inhibits TRAIL-mediated apoptosis and attenuates the therapeutic activity of TRAIL in cancer management. Hypoxia-inducible factor- $1 \alpha(\mathrm{HIF}-1 \alpha)$ plays a central role in tumor hypoxia by up-regulating gene expression related to angiogenesis, cancer invasion and antiapoptosis. Sulforaphane (SFN), a phenethyl isothiocyanate, elicits HIF-1 $\alpha$ inactivation under hypoxia. This study investigated whether hypoxic inhibition of TRAIL-mediated tumor cell death is increased by SFN-mediated HIF-1 $\alpha$ instability. SFN induced cell death in various tumor cells, including SK-N-SH, SNU-638, HeLa and A549 cells, and showed cell cytotoxicity in hypoxia-exposed tumor cells. Western blot analysis showed that SFN treatment increased p53 and activated caspase- 3 proteins, and decreased HIF-1 $\alpha$ activation under hypoxia. Under low-oxygen conditions, TRAIL-treated cells displayed inhibited apoptosis, while SFN-pre-treated cells exhibited stronger sensitization to TRAIL under the hypoxic conditions. SFN treatment enhanced TRAIL-induced activation of proteins, including caspase-3 and p53. SFN dosedependently decreased HIF-1 $\alpha$ protein levels in cancer cells, which was mediated by decreased protein stability. This study demonstrated that SFN recovered hypoxia-mediated resistance to TRAIL via instability of HIF-1 $\alpha$, and also suggests that combination therapy with SFN and TRAIL may provide a novel strategy for treating hypoxic solid tumors.
\end{abstract}

Correspondence to: Dr Sang-Youel Park, College of Veterinary Medicine, Chonbuk National University, Jeonju, Jeonbuk 561-756, Korea

E-mail: sypark@chonbuk.ac.kr

Key words: sulforaphane, hypoxia-inducible factor-1 $\alpha$, tumor necrosis factor-related apoptosis-inducing ligand, hypoxia

\section{Introduction}

The programmed mode of cell death known as apoptosis can be triggered in tumor cells by anti-cancer agents $(1,2)$. Tumor necrosis factor (TNF)-related apoptosis-inducing ligand (TRAIL), a member of the TNF family, is one of the stimuli that induces cancer cell death. TRAIL is of interest in oncology, since it displays specific anti-cancer activity against a wide range of cancer cells without significant side effects (3). In particular, some reports have shown that TRAIL induces apoptosis via a p53-mediated increase of DR5 $(4,5)$. Additionally, one early study found that a number of tumor cell lines expressing wild-type p53 were significantly more sensitive to TRAIL as compared to mutations in p53 genes (6). Thus, TRAIL-mediated apoptosis has been related to p53 tumor suppressor functions during cancer therapy.

Hypoxia is a common stressor of tumors. In particular, rapidly-growing solid tumor cells are often hypoxic at their center. Hypoxia exhibits anti-apoptotic potential via dysregulation of a variety of apoptosis pathways, and decreases the effectiveness of anticancer drugs, including TRAIL, in solid tumor cells $(7,8)$. Hypoxia-inducible factor-1 (HIF-1), a transcriptional factor composed of $\alpha$ - and $\beta$ - subunits, is a key regulator of metabolic adaptation to hypoxia (9). HIF-1 $\alpha$ expression is negatively regulated by the von Hippel-Lindau (pVHL) tumor suppressor gene. HIF-1 $\alpha$ is hydroxylated at prolyl residues under normoxic conditions, thereby targeting the ubiquitin system (10). By contrast, under hypoxic conditions HIF-1 $\alpha$ acts as the primary transcription factor functioning to activate multiple target genes (10). Targets of HIF-1 $\alpha$ include cytokines and growth factors, angiogenesispromoting genes, cell cycle progression, glucose uptake and metabolism, and cell survival. Thus, HIF-1 $\alpha$ has been implicated as an oncogene that is overexpressed in human cancer cells (11). Appropriately, blockade of HIF-1 $\alpha$ as a therapeutic target alone or in combination with chemotherapeutic reagents has been explored. HIF-1 $\alpha$ has also been implicated as a co-regulator of transcription with p53 to promote apoptosis (12). Indeed, the apoptotic function of p53 can be regulated by the status of HIF- $1 \alpha$ in cells, and blocking HIF-1 $\alpha$ expression drives p53-mediated tumor cell death in hypoxia $(13,14)$.

Sulforaphane (SFN), an isothiocyanate derived from the hydrolysis of glucoraphanin in broccoli, induces phase II 
detoxification enzymes and inhibits chemically-induced mammary tumors in rodents (15). Recently, SFN was demonstrated to induce cell cycle arrest and apoptosis in human cancer cells (16). In addition, the compound is safe and essentially non-toxic, making it an excellent candidate as a chemoprevention agent. Recently, it was reported that SFN inhibits the proliferation of human cancer cells by inducing HIF-1 $\alpha$ instability (17). However, the effect of the combination of SFN and TRAIL under hypoxic conditions has not been reported. The present study investigated whether SFN diminishes the hypoxic inhibition of TRAIL-induced apoptosis via the down-regulation of HIF-1 $\alpha$, and also indicates that SFN may act as a sensitizer for hypoxia-induced TRAIL-resistant cancer cells.

\section{Materials and methods}

Cell culture and hypoxic treatment. Human neuroblastoma cells (SK-N-SH), human uterine cervical cancer cells (HeLa), human alveolar basal epithelial cell (A549) and a human gastric cancer cell line (SNU 638) were obtained from the American Type Culture Collection (ATCC). Cells were cultured in Minimum Essential Medium (MEM; Hyclone) containing $10 \%$ fetal bovine serum (Gibco) and gentamycin $(0.1 \mathrm{mg} / \mathrm{ml})$ in a humidified incubator maintained at $37^{\circ} \mathrm{C}$ and $5 \% \mathrm{CO}_{2}$. A hypoxia chamber was used to create a low-oxygen environment; a gas mixture of $1 \% \mathrm{O}_{2}, 5 \% \mathrm{CO}_{2}$ and $94 \% \mathrm{~N}_{2}$ flowed into the sealed chamber. Ambient air was evacuated by an outlet tube and $\mathrm{O}_{2}$ flowed through the chamber for 2-3 min to maintain the desired $\mathrm{O}_{2}$ tension.

Crystal violet assay. Cell viability was determined by crystal violet staining as previously described (18). Briefly, cells were stained with staining solution $(0.5 \%$ crystal violet in $30 \%$ ethanol and $3 \%$ formaldehyde) for $10 \mathrm{~min}$ at room temperature (RT), washed four times with water and dried. Cells were then lysed with $1 \%$ sodium dodecyl sulfate (SDS) solution and cell absorbance was measured at $550 \mathrm{~nm}$. Cell viability was calculated based on the relative dye intensity compared to the controls.

Terminal deoxynucleotidyl transferase dUTP nick end labeling (TUNEL) assay. TUNEL analysis was performed to measure the degree of cellular apoptosis using an in situ ApoBrdU DNA fragmentation assay kit (BioVision, CA, USA) following the manufacturer's instructions.

DNA fragmentation assay. Cell pellets were suspended in $0.5 \mathrm{ml}$ of $50 \mathrm{mM}$ Tris- $\mathrm{HCl}$ buffer $(\mathrm{pH} 8.0)$ containing $10 \%$ (v/v) NP-40, 20 mM EDTA and 0.5\% (w/v) SDS, and digested with $500 \mu \mathrm{g} / \mathrm{ml}$ proteinase $\mathrm{K}$ for $4 \mathrm{~h}$ at $65^{\circ} \mathrm{C}$. After digestion, the DNA was sequentially extracted with phenol/chloroform $(1: 1, \mathrm{v} / \mathrm{v})$ and precipitated with ethanol at $-20^{\circ} \mathrm{C}$ overnight. Purified DNA was electrophoresed on a $1.5 \%$ agarose gel and visualized by ethidium bromide staining and ultraviolet transillumination.

Immunofluorescence. Cell lines cultured on glass coverslips were treated with SFN (Sigma) and/or TRAIL. Cells were washed with phosphate buffered saline (PBS) and fixed with cold acetone for $90 \mathrm{sec}$ at RT. Cells were then washed with PBS again, blocked with 5\% fetal bovine serum (FBS) in tris buffered saline with Tween (TBST) and incubated with anticaspase-3 $(2 \mu \mathrm{g} / \mathrm{ml})$ and anti-HIF-1 $\alpha(2 \mu \mathrm{g} / \mathrm{ml})$ monoclonal antibodies for $48 \mathrm{~h}$ at RT. Unbound antibody was removed by an additional PBS wash and cells were incubated with labeled anti-rabbit Alexa Fluor 546 (for anti-caspase-3 and antiHIF- $1 \alpha) \mathrm{IgG}$ antibodies ( $4 \mu \mathrm{g} / \mathrm{ml})$ for $2 \mathrm{~h}$ at RT. Finally, cells were mounted with DakoCytomation fluorescent medium and visualized using fluorescence microscopy.

$R T$-PCR. Total RNA was isolated using RNAiso Plus (Takara). cDNA synthesis was performed using the Takara Prime Script $^{\mathrm{TM}}$ first strand cDNA synthesis kit (200 U/ $\left.\mu \mathrm{l}\right)$ according to the manufacturer's instructions. HIF-1 $\alpha$ specific primer sequences (forward, 5'-AGAAACCACCTATGACCTGC-3'; reverse, 5'-GTCGTGCTGAATAATACCACTC-3') and $\beta$-actinspecific primer sequences (forward, 5'-GCAAGCAGGAGT ATGACGAG-3'; reverse, 5'-CAAATAAAGCCATGCCAA TC-3') were used for RT-PCR. Each $50 \mu \mathrm{l}$ of amplification reaction contained 1.25 units of Taq polymerase, $2.5 \mathrm{mM}$ dNTP mixture, $20 \mathrm{pM}$ primers and $2 \mu \mathrm{l}$ cDNA for each gene. The PCR parameters were 30 cycles as follows: denaturation at $94^{\circ} \mathrm{C}$ for $30 \mathrm{sec}$, annealing at $55-60^{\circ} \mathrm{C}$ for $30 \mathrm{sec}$, and extension at $72^{\circ} \mathrm{C}$ for $1 \mathrm{~min}$. The PCR products were separated on $1.2 \%$ agarose electrophoresis gels, stained with $0.5 \mu \mathrm{g} / \mathrm{ml}$ ethidium bromide and recorded for analysis.

Western blotting. Cell lines were lysed in a lysis buffer (25 mM HEPES; pH 7.4, 100 mM NaCl, 1 mM EDTA, 5 mM $\mathrm{MgCl}_{2}, 0.1 \mathrm{mM}$ DTT and protease inhibitor mixture). Proteins were electrophoretically resolved on an $8-15 \%$ SDS gel, and immunoblotting was performed as previously described (19). Equal amounts of protein lysates were resolved on an 8-15\% SDS-polyacrylamide gel and electrophoretically transferred to a nitrocellulose membrane. Immunoreactivity was detected through sequential incubation with horseradish peroxidaseconjugated secondary antibodies and ECL reagents. The antibodies used for immunoblotting were p53, HIF-1 $\alpha$ and $\beta$-actin (Santa Cruz, CA, USA).

Statistical evaluation. All data are expressed as the means \pm standard deviations (SD) and were compared using the Student's t-test and the ANOVA Duncan test with the SAS statistical package. The results were considered significant for values of ${ }^{*} \mathrm{P}<0.05$ or ${ }^{* *} \mathrm{P}<0.01$.

\section{Results}

SFN induces cancer cell apoptosis under normoxia or hypoxia. Hypoxia inhibits TRAIL-mediated apoptosis (8). On the other hand, SFN is an anti-cancer therapeutic agent that decreases HIF-1 $\alpha$ activation under low-oxygen conditions (17). Appropriately, the present study examined the influence of hypoxia on SFN- or TRAIL-induced cell death in SK-N-SH, SNU-638, HeLa and A549 cancer cells. Crystal violet staining showed that all cell types were sensitive to SFN with or without hypoxia (40-60\% reduction in viability of all cell populations) (Fig. 1A and C). On the other hand, hypoxia-exposed cells were resistant to TRAIL treatment 


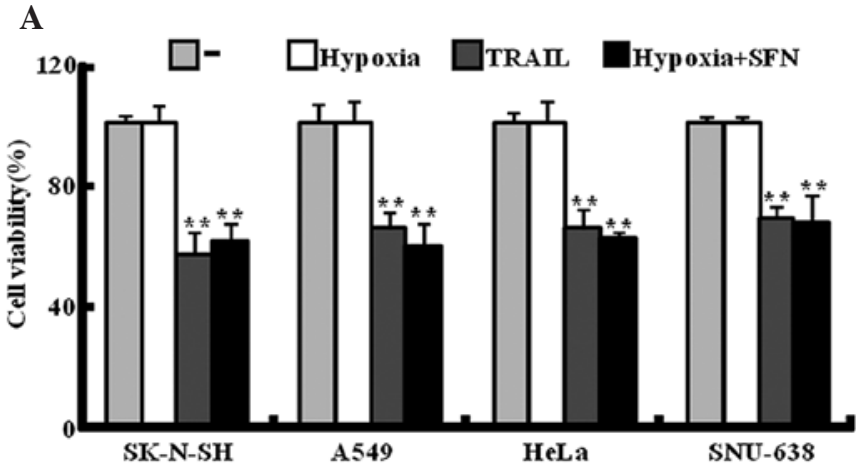

B

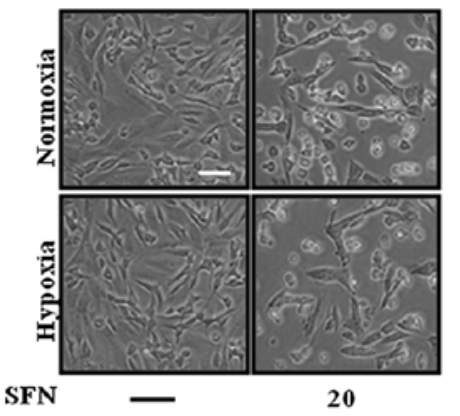

C

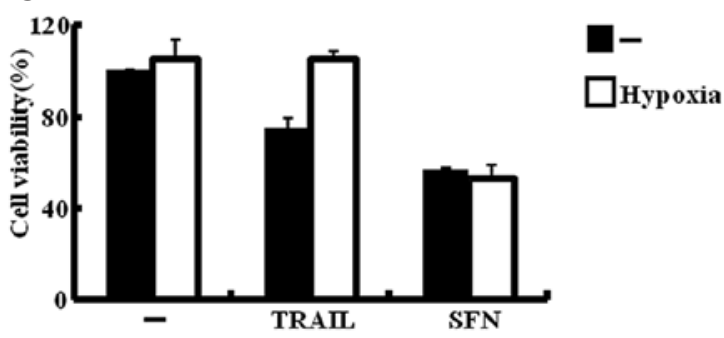

D

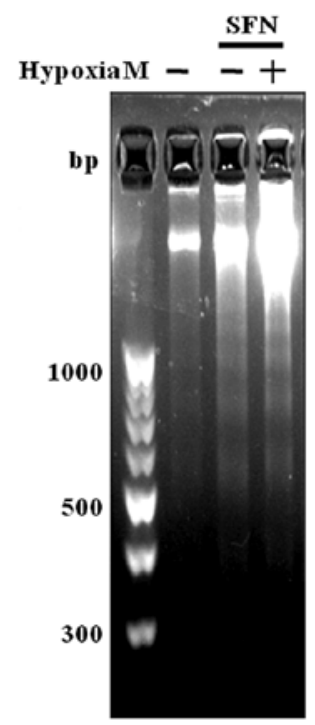

Figure 1. SFN induces apoptosis in hypoxic cancer cells. (A) All cancer cells were pre-incubated under hypoxic conditions for $12 \mathrm{~h}$, and then exposed to $20 \mu \mathrm{M}$ SFN for $24 \mathrm{~h}$. The viability of the treated cells was measured by crystal violet staining, and is presented relative to that of the control cells, which was set at $100 \%$. (B) Cell morphology was photographed with a light microscope (magnification, x200; scale, $200 \mu \mathrm{m}$ ). (C) SK-N-SH cells were pre-incubated under hypoxic conditions for $12 \mathrm{~h}$, and then exposed to $20 \mu \mathrm{M}$ SFN for $24 \mathrm{~h}$ or to $400 \mathrm{ng} / \mathrm{ml}$ TRAIL for $6 \mathrm{~h}$. Viability was measured and presented as described above. (D) Analysis of genomic DNA isolated from SK-N-SH cells treated with $400 \mathrm{ng} / \mathrm{ml}$ TRAIL under hypoxia or normoxia. Marker, 100-bp DNA ladder.
(Fig. 1C). To confirm whether SFN induced cell death, the morphology of SK-N-SH cells exposed to $20 \mu \mathrm{M}$ SFN for $24 \mathrm{~h}$ and/or hypoxia was examined. Morphologic changes were observed in SFN-treated cells with or without hypoxia (Fig. 1B). Furthermore, SFN induced DNA fragmentation in SK-N-Sh cells under normoxia or hypoxia (Fig. 1D).

SFN induces apoptotic signaling under hypoxic conditions through HIF-1 $\alpha$ inactivation. SFN decreases HIF-1 $\alpha$ stability under hypoxia (17). Thus, immunocytochemistry was performed using an antibody against HIF-1 $\alpha$. Cells were treated with $20 \mu \mathrm{M}$ SFN with or without hypoxia. The results showed that HIF-1 $\alpha$ was detectable upon exposure to hypoxia and was decreased by SFN treatment (Fig. 2A). Since HIF-1 $\alpha$ is known to negatively regulate p53 (14), the possible involvement in SFN-induced apoptosis was ascertained by immunoblot analysis using antibodies against HIF-1 $\alpha$ and p53 (Fig. 2B). SFN-treated cells displayed increased expression of p53 protein under normoxia or hypoxia, while HIF-1 $\alpha$ protein levels were decreased under hypoxia. These results are consistent with an effect of SFN on the expression of p53 protein levels via decreased HIF-1 $\alpha$ protein expression under hypoxia. Analysis of mRNA expression showed that HIF-1 $\alpha$ gene transcription was not affected by SFN under normoxia or hypoxia (Fig. 2C), indicating that SFN affected HIF-1 $\alpha$ stabilization under hypoxia. Additionally, since SFN is a cancer therapeutic agent, immunocytochemistry analysis was performed using an antibody against the cleaved fragment of caspase-3, which is a key substrate for apoptosis. Cleaved caspase-3 was detectable in SFN-treated cells (Fig. 2D), indicating that SFN induced apoptosis through decreased HIF-1 $\alpha$ stabilization and increased p53 expression and the activation of caspase-3 cleavage.

SFN recovers hypoxic inhibition of TRAIL-mediated apoptosis by HIF-l $\alpha$ instability. To determine whether HIF-1 $\alpha$ instability is a mechanism of SFN-induced apoptosis under hypoxic conditions, an experiment was conducted in solid tumor cells to address the hypothesis that SFN-induced suppression of HIF-1 $\alpha$ stabilization recovers TRAIL-induced apoptosis under hypoxia. This effect of SFN was observed in all cell lines (Fig. 3A). A reduction in cell viability of $40-50 \%$ was evident in SFN pre-treated cells subsequently exposed TRAIL with or without hypoxia. The data was further corroborated by morphologic examination of hypoxic cells, which revealed a significant increase in the cell death of SFN and TRAIL combination-treated cells compared to cells treated only with TRAIL (Fig. 3B). Treatment with SFN and TRAIL increased p53 and decreased HIF-1 $\alpha$ protein expression under hypoxia (Fig. 4A). Immunofluorescent analysis using an antibody against cleaved caspase-3 detected the cleavage product in SK-N-SH cells exposed to SFN and TRAIL under hypoxic conditions (Fig. 4B). The results of a TUNEL assay also showed elevated sensitivity to TRAIL protein in hypoxic tumor cells (Fig. 4C). The results indicate that HIF-1 $\alpha$ activity suppressed by SFN sensitized hypoxic tumor cells to TRAIL-induced apoptosis.

\section{Discussion}

The main focus of this study was the investigation of the therapeutic potential of the HIF-1 $\alpha$ suppressor compound SFN 
A

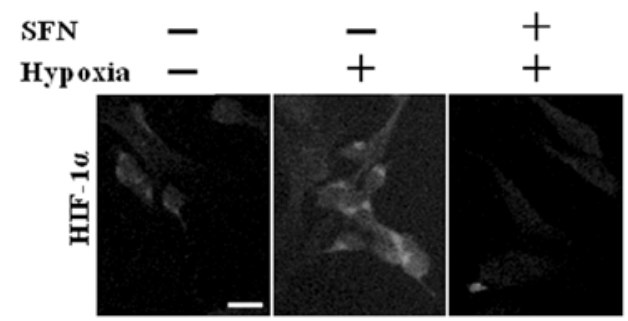

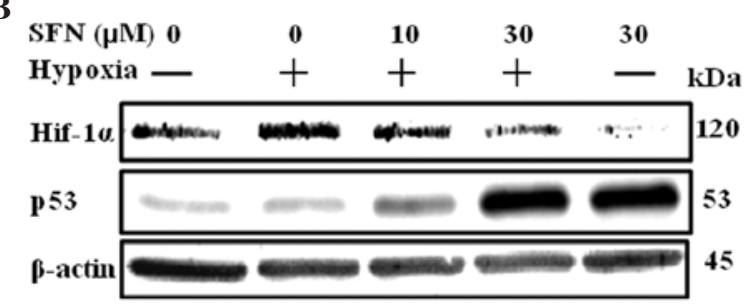

C

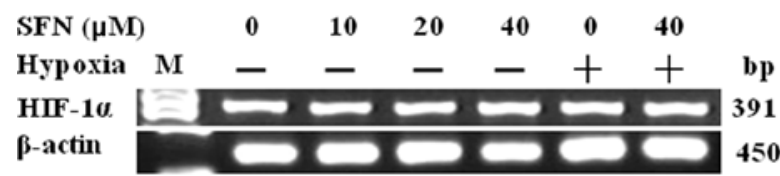

$\mu$
D

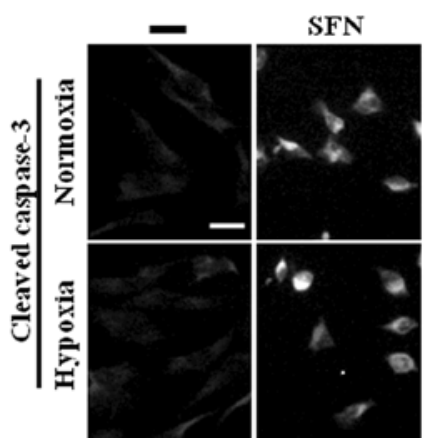

Figure 2. SFN induces apoptosis in hypoxic tumor cells by HIF-1 $\alpha$ inactivation. (A) For the immunocytochemical analysis of HIF-1 $\alpha$ in SK-N-SH cells, cells were pre-incubated under hypoxic conditions for $12 \mathrm{~h}$, and then exposed to $20 \mu \mathrm{M}$ SFN for $12 \mathrm{~h}$. Scale bar, $50 \mu \mathrm{m}$. (B) Western blot analysis of HIF-1 $\alpha$ in SK-N-SH cells pre-incubated under hypoxic conditions for $12 \mathrm{~h}$, and then treated with $20 \mu \mathrm{M} \mathrm{SFN}$ for $12 \mathrm{~h}$. $\beta$-actin was used as a loading control. (C) Transcription level of HIF-1 $\alpha$ determined in SK-N-SH cells after exposure to hypoxia with or without SFN. Cells were pre-incubated under hypoxic conditions for $12 \mathrm{~h}$ in the absence of SFN or the presence of various concentrations of SFN for $12 \mathrm{~h}$. Total RNA was extracted and semi-quantitative RT-PCR was performed. $\beta$-actin served as an internal control. (D) Immunocytochemistry of cleaved caspase-3 in SK-N-SH cells. Cells were pre-incubated under hypoxic conditions for $12 \mathrm{~h}$, and then exposed to $20 \mu \mathrm{M}$ SFN for $12 \mathrm{~h}$. Scale bar, $100 \mu \mathrm{m}$.

A

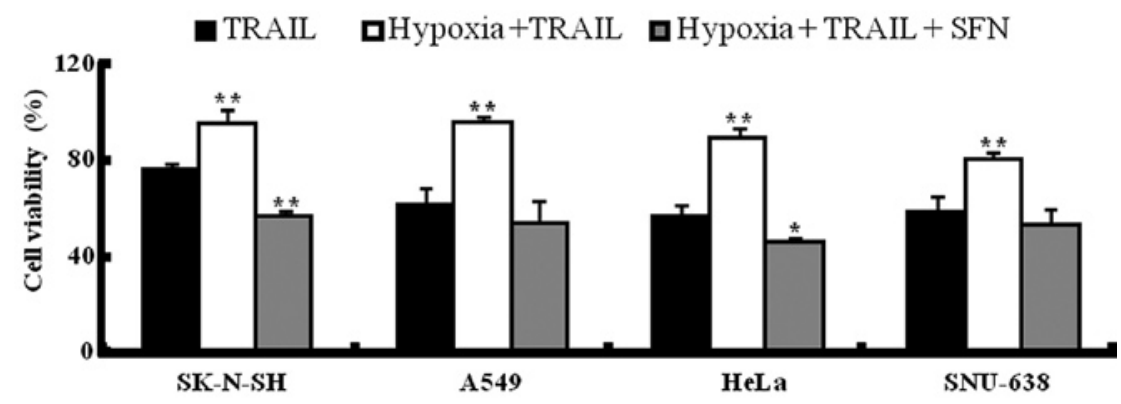

B

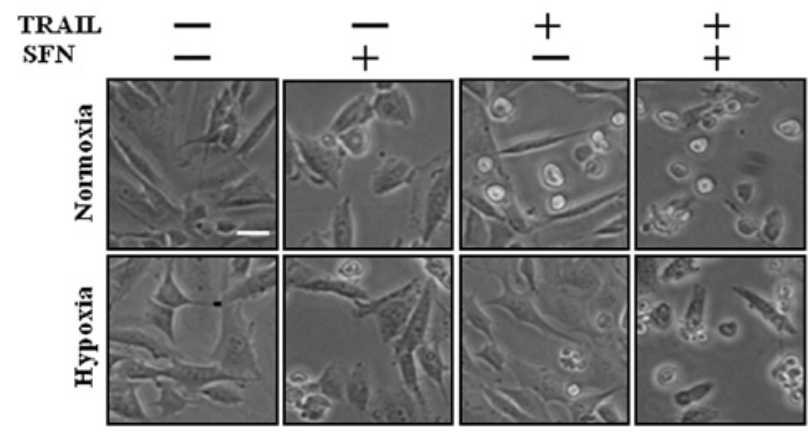

Figure 3. SFN maintains TRAIL-induced apoptosis under hypoxia. (A) All cancer cells were pre-incubated under hypoxic conditions for $12 \mathrm{~h}$ prior to exposure to $10 \mu \mathrm{M} \mathrm{SFN}$ for $24 \mathrm{~h}$ in the absence of TRAIL or presence of $400 \mathrm{ng} / \mathrm{ml}$ TRAIL for $6 \mathrm{~h}$. Cell viability was measured and expressed as described in Fig. 1A. (B) Cell morphology was photographed with a light microscope (magnification, x200; scale bar, $50 \mu \mathrm{m}$ ).

in therapeutic intervention strategies using TRAIL protein against hypoxic solid tumors.

In response to hypoxia, cells alter their metabolism and regulation of gene expression to adapt to hypoxia (9). Previous studies have shown that hypoxic tumor cells block many different therapies through the increased expression of HIF-1 $\alpha$, Bcl-2 and IAP family members, while decreasing the expression of the p53 and caspase family (7,20). Consistent with these results, in the present study the expression of $\mathrm{p} 53$ protein was decreased and the expression of HIF-1 $\alpha$ was 
A

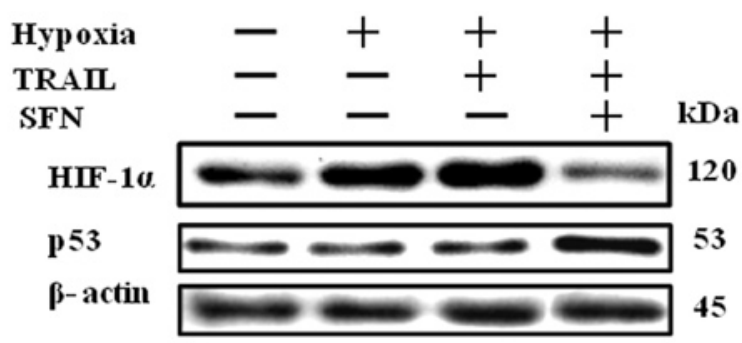

B

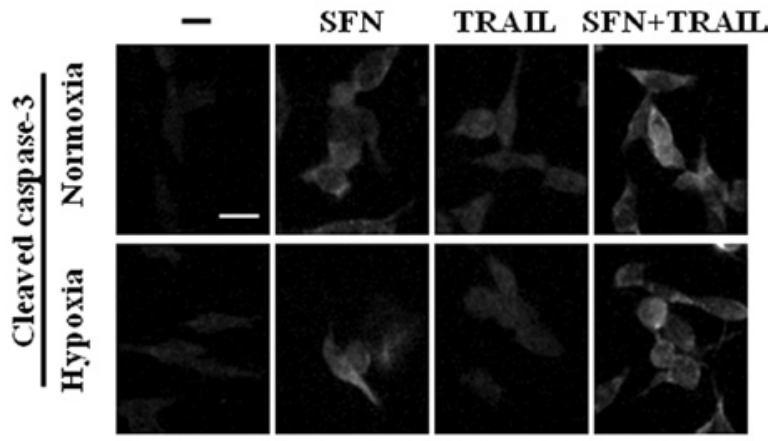

C
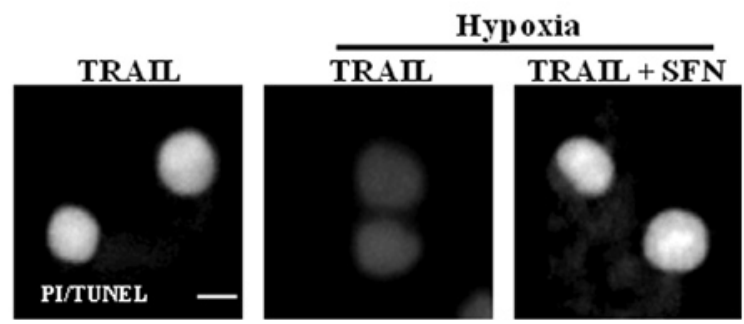

Figure 4. SFN recovers TRAIL-mediated apoptosis under low-oxygen conditions via HIF-1 $\alpha$ instability. (A) Western blot analysis of HIF-1 $\alpha$ and p53 in SK-N-SH cells. Cells were pre-incubated under hypoxic conditions for $12 \mathrm{~h}$, and then exposed to $10 \mu \mathrm{M}$ SFN for $12 \mathrm{~h}$ in the absence of TRAIL or presence of $400 \mathrm{ng} / \mathrm{ml}$ TRAIL for $6 \mathrm{~h}$. $\beta$-actin served as the loading control. (B) Immunocytochemistry of cleaved caspase-3 in SK-N-SH cells. Cells were pre-incubated under hypoxic conditions for $12 \mathrm{~h}$, and then exposed to $10 \mu \mathrm{M}$ SFN for $12 \mathrm{~h}$ in the absence of TRAIL or presence of $400 \mathrm{ng} / \mathrm{ml}$ TRAIL for $6 \mathrm{~h}$. Scale bar, $100 \mu \mathrm{m}$. (C) Representative immunofluorescence images of TUNEL-positive (white) SK-N-SH cells pre-incubated with hypoxia and then with $10 \mu \mathrm{M}$ SFN for $12 \mathrm{~h}$ in the absence of TRAIL or presence of $400 \mathrm{ng} / \mathrm{ml}$ TRAIL. The cells were counterstained with propidium iodide (grey) to show all cell nuclei. Scale bar, $20 \mu \mathrm{m} .{ }^{*} \mathrm{P}<0.01,{ }^{* *} \mathrm{P}<0.05$, significant differences between the control and each treatment group.

increased in SK-N-SH cells, independent of TRAIL treatment under hypoxia (Fig. 4A). A recent study suggested that HIF-1 $\alpha$ increases the expression of a decoy receptor that has an important role in impeding TRAIL-induced apoptosis under hypoxia (21). Consistent with this, SFN-mediated inactivation of HIF-1 $\alpha$ (Fig. 2) enhanced TRAIL-mediated therapeutic efficacy under hypoxia (Fig. 3). Thus, the inactivation of HIF-1 $\alpha$ appears to be essential for the recovery of TRAILinduced therapeutic effect in solid tumors.

Several reports have indicated that $\mathrm{SFN}$ is a promising chemotherapeutic agent due to its inducion of apoptosis and cell-cycle arrest in a variety of tumors $(22,23)$. Accordingly, the present study assessed the effect of SFN in solid tumor cells under hypoxic conditions. SFN induced apoptosis with or without hypoxia (Fig. 1), and decreased HIF-1 $\alpha$ protein levels and enhanced p53 protein levels under the low-oxygen conditions (Fig. 2B). These observations support the view that the hypoxia-mediated apoptotic effect of SFN may result, at least in part, from HIF-1 $\alpha$ inactivation. These findings indicate that natural products that suppress HIF-1 $\alpha$ have potential use as a therapeutic tool in combination with TRAIL against hypoxic tumors cells.

Taken together, the present results demonstrate that the hypoxic inhibition of TRAIL-mediated therapeutic activity is recovered by SFN-mediated HIF-1 $\alpha$ inactivation, and also indicate that HIF-1 $\alpha$ inactivation reagents or natural compounds, including SFN, may have therapeutic benefits in hypoxic tumor cells, particularly in anti-cancer therapy using TRAIL peptide.

\section{Acknowledgements}

This study was supported by a grant from the National Research Foundation of Korea funded by the Korean Government (2010-17204), the Regional Research Universities Program and the Center for Healthcare Technology Development.

\section{References}

1. Hickman JA: Apoptosis induced by anticancer drugs. Cancer Metastasis Rev 11: 121-139, 1992.

2. Zhang JY: Apoptosis-based anticancer drugs. Nat Rev Drug Discov 1: 101-102, 2002.

3. Gura T: How TRAIL kills cancer cells, but not normal cells. Science 277: 768, 1997.

4. Kim K, Takimoto R, Dicker DT, Chen Y, Gazitt Y and El-Deiry WS: Enhanced TRAIL sensitivity by p53 overexpression in human cancer but not normal cell lines. Int J Oncol 18: 241-247, 2001.

5. Nagane M, Huang HJ and Cavenee WK: The potential of TRAIL for cancer chemotherapy. Apoptosis 6: 191-197, 2001.

6. Takimoto R and El-Deiry WS: Wild-type p53 transactivates the KILLER/DR5 gene through an intronic sequence-specific DNA-binding site. Oncogene 19: 1735-1743, 2000.

7. Selvendiran K, Bratasz A, Kuppusamy ML, Tazi MF, Rivera BK and Kuppusamy P: Hypoxia induces chemoresistance in ovarian cancer cells by activation of signal transducer and activator of transcription 3. Int J Cancer 125: 2198-2204, 2009.

8. Park SY, Billiar TR and Seol DW: Hypoxia inhibition of apoptosis induced by tumor necrosis factor-related apoptosisinducing ligand (TRAIL). Biochem Biophys Res Commun 291: $150-153,2002$.

9. Ryan HE, Lo J and Johnson RS: HIF-1 alpha is required for solid tumor formation and embryonic vascularization. EMBO J 17: 3005-3015, 1998.

10. Haase VH: The VHL tumor suppressor: master regulator of HIF. Curr Pharm Des 15: 3895-3903, 2009.

11. Koh MY, Spivak-Kroizman TR and Powis G: HIF-1alpha and cancer therapy. Recent Results Cancer Res 180: 15-34, 2010.

12. Ravi R, Mookerjee B, Bhujwalla ZM, et al: Regulation of tumor angiogenesis by p53-induced degradation of hypoxia-inducible factor 1alpha. Genes Dev 14: 34-44, 2000.

13. Schmid T, Zhou J and Brune B: HIF-1 and p53: communication of transcription factors under hypoxia. J Cell Mol Med 8: 423-431, 2004.

14. Sendoel A, Kohler I, Fellmann C, Lowe SW and Hengartner MO: HIF-1 antagonizes p53-mediated apoptosis through a secreted neuronal tyrosinase. Nature 465: 577-583, 2010.

15. Clarke JD, Dashwood RH and Ho E: Multi-targeted prevention of cancer by sulforaphane. Cancer Lett 269: 291-304, 2008.

16. Li Y, Zhang $\mathrm{T}$, Korkaya $\mathrm{H}$, et al: Sulforaphane, a dietary component of broccoli/broccoli sprouts, inhibits breast cancer stem cells. Clin Cancer Res 16: 2580-2590, 2010.

17. Yao $\mathrm{H}$, Wang $\mathrm{H}$, Zhang $\mathrm{Z}$, Jiang $\mathrm{BH}$, Luo $\mathrm{J}$ and Shi $\mathrm{X}$ : Sulforaphane inhibited expression of hypoxia-inducible factor1alpha in human tongue squamous cancer cells and prostate cancer cells. Int J Cancer 123: 1255-1261, 2008. 
18. Seol JW, Chaudhari AA, Lee YJ, et al: Regulation of DR-5 protein and mitochondrial transmembrane potential by gemcitabine, a possible mechanism of gemcitabine-enhanced TRAIL-induced apoptosis. Oncol Rep 18: 523-529, 2007.

19. Seo JS, Seol JW, Moon MH, Jeong JK, Lee YJ and Park SY: Hypoxia protects neuronal cells from human prion protein fragment-induced apoptosis. J Neurochem 112: 715-722, 2010.

20. Gardner LB and Corn PG: Hypoxic regulation of mRNA expression. Cell Cycle 7: 1916-1924, 2008.

21. Pei GT, Wu CW and Lin WW: Hypoxia-induced decoy receptor 2 gene expression is regulated via a hypoxia-inducible factor lalpha-mediated mechanism. Biochem Biophys Res Commun 391: 1274-1279, 2010
22. Nishikawa T, Tsuno NH, Tsuchiya T, et al: Sulforaphane stimulates activation of proapoptotic protein bax leading to apoptosis of endothelial progenitor cells. Ann Surg Oncol 16: 534-543, 2009.

23. Pledgie-Tracy A, Sobolewski MD and Davidson NE: Sulforaphane induces cell type-specific apoptosis in human breast cancer cell lines. Mol Cancer Ther 6: 1013-1021, 2007. 